\title{
EDITORIAL
}

\section{AUTONOMIC NEUROPATHY AND CARDIOVASCULAR DISEASE IN AGING}

\author{
A. SHAMS ${ }^{1}$, MORLEY $^{2}$

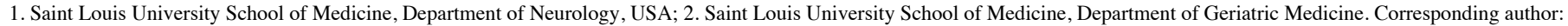 \\ John E. Morley, MB, BCh, Division of Geriatric Medicine, Saint Louis University School of Medicine, 1402 S. Grand Blvd., M238, St. Louis, MO 63104, \\ Email: john.morley@health.slu.edu
}

Similar to any other systems in the human body, the nervous system undergoes functional decline with aging. These changes have been identified in both central and peripheral components of the nervous systems including the somatic and autonomic branches. Some of the well-known neurological deficits which are associated with aging are hyperopia, presbycusis, diminished sense of taste and smell, loss or impairment of vibratory sense in ankles, and toes, and reduced number of motor end units (1). The autonomic nervous system (ANS) is the nervous system which maintains homeostasis by regulating the function of the heart, the endocrine and exocrine glands, the abdominal viscera, the smooth muscles throughout the body, and the immune system (2) (Figure 1). The ANS is divided into two divisions: the sympathetic thoracolumbar chain outflow and parasympathetic craniosacral outflow (3). Multiple hypotheses have been proposed about changes which occur to the ANS secondary to aging. These appear to be predominantly due to a decline in receptor functionality $(4,5)$.

\section{Orthostatic Hypotension}

Orthostatic hypotension $(\mathrm{OH})$ has been defined as drop in $20 \mathrm{mmHg} \leq$ in systolic blood pressure or $10 \mathrm{mmHg} \leq$ in diastolic blood pressure within 3 minutes of standing from supine position (6-10). It has been shown that orthostatic hypotension prevalence increases with age and it is present in $70 \%$ of institutionalized elderly individuals (11). The prevalence of $\mathrm{OH}$ among unselected elderly aged $70 \leq$ is between 6 to $30 \%$ (1214). The occurrence of $\mathrm{OH}$ is higher in females than males and more common in blacks than whites $(15,16)$.

Some long term outcomes of $\mathrm{OH}$ are syncope, falls, fracture, and motor vehicle accidents (17). A meta-analysis found that $\mathrm{OH}$ was associated with increased mortality (OR 1.5 (1.211.81) (18). The mortality increase was greater in those younger than 65 years. Orthostatic hypotension has been associated with chronic heart failure (19), neurodegenerative diseases (20), frailty (21), diabetes (22), hypertension (23), atrial fibrillation (22), coronary artery disease $(24,25)$, and ischemic stroke (26). OH may or may not be symptomatic, but it technically is different from what has been described as orthostatic intolerance (OI) which is defined as symptomatic hypotension upon upright position (27). Frailty is a common condition in older patients and has been shown to predict $\mathrm{OI}(\mathrm{OH}$ yes) $(26$, 29, 30).
Although the majority of patients with $\mathrm{OH}$ are either asymptomatic or only experience very few non-specific symptoms, as a result of decreased cerebral hypoperfusion secondary to $\mathrm{OH}$, some patients may experience visual blurring, lightheadedness, dizziness, nausea, fatigue, and syncope (30).

In a normal healthy individual, standing will result in decreased venous return and subsequently reduced stretch of the afferent baroreceptors in both carotid sinuses and aortic arch. These baroreceptors are electromechanical transducers (31). Decreased transmural pressure from the aortic baroreceptor is detected and the signal is transmitted through the vagus nerve ( $\mathrm{CN} \mathrm{X)}$ to the dorsal medullary nuclei bilaterally which are called nucleus tractus solitarii (NTS). Finally, inhibitory interneurons which extend from each NTS nucleus into the rostral ventrolateral medulla result in a vasoconstriction response (31).

\section{Figure 1}

Cardiovascular Syndromes Due to Autonomic Neuropathy in Older Persons

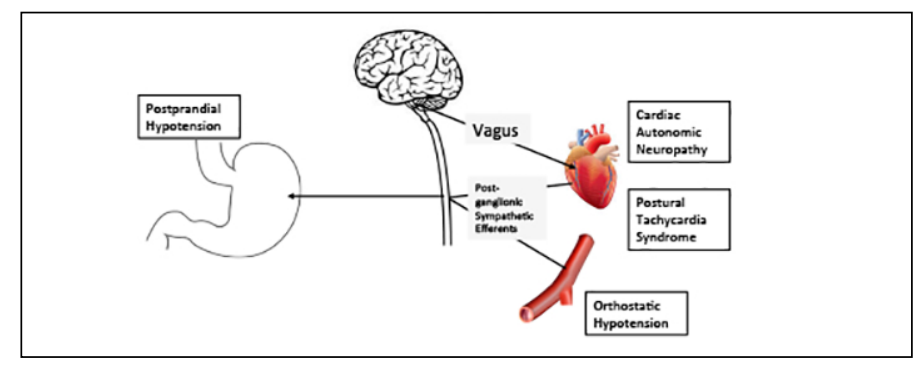

The etiology of orthostatic hypotension is divided in two main categories: neurogenic and cardiovascular. The neurogenic causes of $\mathrm{OH}$ can be central (also known as primary autonomic degenerative disorders) and peripheral disorders of autonomic nervous systems. Primary autonomic degenerative disorders which disrupt the autonomic portion of the central nervous system (CNS) are multiple-system atrophy, dementia with Lewy bodies, Parkinson's disease, and pure autonomic failure (7). Peripheral disorders of autonomic nervous systems are mainly due to malfunctioning of the small fibers of the peripheral nerves which is typically observed in amyloidosis, diabetes, immune-mediated neuropathies, inflammatory neuropathies, neurotoxins, infection induced neuropathies, paraneoplastic syndromes, porphyria and vitamin B12 


\section{THE JOURNAL OF NUTRITION, HEALTH \& AGINGC}

Table 1

Medications used for the treatment of orthostatic hypotension

\begin{tabular}{lccc}
\hline Medication & Mechanism of Action & Dosage Form & Dose \& Frequency \\
\hline Fludrocortisone & Potent mineralocorticoid & Tablet & $0.1-0.4 \mathrm{mg}$ daily \\
Midodrine & $\alpha 1$-Adrenergic agonist & Tablet & $5 \mathrm{mg}$ daily \\
Octreotide & Increase splanchnic and peripheral vascular resistance & Subcutaneously & $25-200 \mu \mathrm{g}$ daily \\
Pyridostigmine & Acetylcholinesterase inhibitor & Tablet & $60-240 \mathrm{mg}$ daily \\
Droxidopa & Precursor synthetic amino acid to norepinephrine & Capsule & $100-600 \mathrm{mg}$ three times a day \\
Atomoxetine & Selectively inhibitor of norepinephrine reuptake & Capsule & $18 \mathrm{mg}$ daily \\
Erythropoietin & Increase systemic blood pressure & Subcutaneously & $25-75 \mathrm{U} / \mathrm{kg}$ daily \\
Desmopressin & V1 and V2 receptor agonist & Nasal spray & $5-40 \mu \mathrm{g}$ daily \\
Yohimbine & $\alpha 2-$ Adrenergic antagonist & Capsule & $5 \mathrm{mg}$ four times a day \\
\hline
\end{tabular}

deficiency $(7,32)$.

Because $\mathrm{OH}$ is so common all patients over 65 years old and those younger with diabetes mellitus or being treated for hypertension should have their standing blood pressure measured at each visit. $\mathrm{OH}$ is only present on about half of the occasions it is measured and it is more common in the morning (33). Medications should also be carefully reviewed for medications that may cause $\mathrm{OH}(9,34)$.

The Valsalva maneuver is a method of evaluation for sympathetic adrenergic dysfunction based on assessment of beat-to-beat blood pressure and heart rate responses to indirectly assess the sympathetic vasoconstrictor function (35, 36). The Valsalva maneuver has been shown to be a reliable assessment for evaluation of the baroreflex sensitivity (37). In a tilt table test the patient is placed in head up position on a tilt table and the table is elevated at an angle of 60 degrees or greater (38). It is rarely necessary to make the diagnosis of $\mathrm{OH}$ in older persons.

In the management of $\mathrm{OH}$, the non-autonomic causes such as Addison disease, anemia, dehydration, and polypharmacy need to be examined and treated $(23,28,39)$. Volume expansion is the initial step of the treatment. Daily fluid intake of 2 to $2.5 \mathrm{~L}$ in addition to sodium intake of 8 to $10 \mathrm{~g}$ has been recommended (6). Patient should be advised to avoid alcohol and have small frequent meals $(6,40)$.

The use of nonpharmacological methods of treatments such as biofeedback and upper body exercises have shown to be noneffective (41). Most commonly used medications for treatment of $\mathrm{OH}$ are listed in table I $(6,16,17,21,42-54)$ :

While the majority of these medications have little evidence supporting their use, fludrocortisone and Droxidopa have both been shown to be effective in treatment of $\mathrm{OH}(37,49,55)$.

\section{Postural Tachycardia Syndrome (POTS)}

POTS is orthostatic intolerance that leads to a tachycardia (pulse increase of $>30$ beats $/ \mathrm{min}$ or $>120 / \mathrm{min}$ within 10 minutes of standing) on standing $(56,57)$. It is associated with dizziness, fainting, fatigue, palpitations, sweating, nausea and headaches. Patients with POTS have impairment of memory, attention deficits and executive function as well as anxiety and depressive symptoms (58). POTS is rarely reported in older persons with age of onset being prior to 50 years of age (59). However, it is found in concert with syncope in older persons due to orthostatic cerebral hypoperfusion syndrome (60). It is more common in diabetics with autonomic dysfunction and multiple sclerosis $(61,62)$. In general, POTS is due either to a decrease in blood return to the brain due to poor sympathetic innervation of peripheral blood vessels leading to sympathetic nervous system outflow leading to cardial stimulation and tachycardia (63) (Figure 2). This can be aggravated by a decrease in peripheral blood volume, Treatment can be very difficult with the first choice being increasing salt intake, compression stockings, abdominal binding and a nonspecific beta blocker (e.g., propranolol) (64).

\section{Postprandial Hypotension}

Postprandial Hypotension (PPH) was initially described in 1977 by Seyer-Hansen as a case report in a patient with a Parkinson disease $(65,66)$. PPH is defined as $20 \mathrm{mmHg} \leq \mathrm{drop}$ in systolic blood pressure within the first 2 hours of food intake or systolic blood pressure of $90<\mathrm{mmHg}$ within 2 hours of having a meal (if SBP prior to having a meal was above 100 $\mathrm{mmHg})(67,68)$. The prevalence of PPH among "healthy" older individuals is between $24 \%$ to $38 \%$ and it increases up to $91 \%$ in hospitalized elderly patients. $(69,70)$. PPH has been associated with old age, autonomic dysfunction, falls, syncope, tabes dorsalis, Parkinson's disease, Alzheimer's disease, stroke, coronary artery disease, hypertension, diabetes mellitus, and increased frequency of all-cause mortality $(1,15,71-76)$. Predisposing risk factors of $\mathrm{PPH}$ are polypharmacy, diuretics, hot meals $(50 \mathrm{C}<)$, rich carbohydrate diet, diabetes mellitus, autonomic dysfunction, Parkinson disease, end-stage renal 


\section{AUTONOMIC NEUROPATHY AND CARDIOVASCULAR DISEASE IN AGING}

disease on hemodialysis, hypertension, and fragile $\mathrm{X}$ mutation (77) (Figure 3).

Patients with PPH may present with lightheadedness, nausea, syncope, fall, chest pain (angina pectoris), or even transient ischemic attack (67). Symptoms are often most prominent in the morning and after breakfast $(78,79)$.

Figure 2

Pathophysiology of the Postural Tachycardia Syndrome

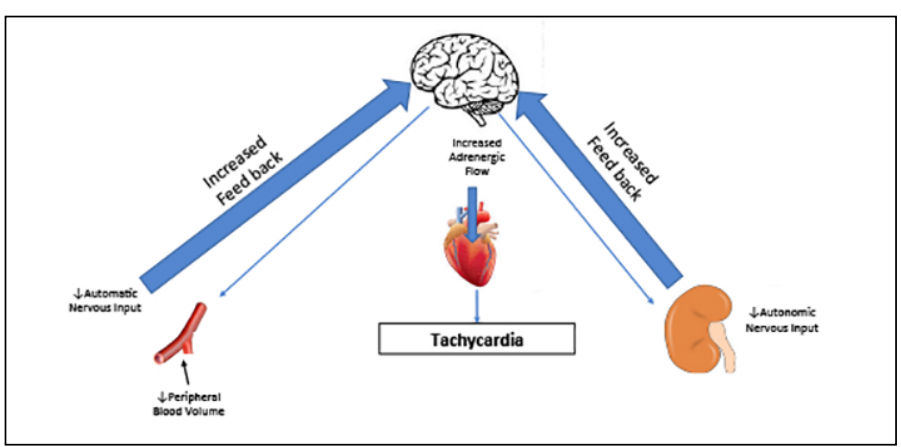

Blood pressure should be measured at least after one meal that patient feels the worst symptoms (77). However, if more measurements are required, an ambulatory blood pressure monitoring (ABPM) for at least 24 hours is suggested (77, 79). Only one positive reading will be sufficient to diagnose PPH. It has been shown that measuring the patient's blood pressure in an upright posture (head-up tilt-table) specifically after consumption of a warm carbohydrate rich meal would exacerbate symptomatic hypotension which would be the ideal time to evaluate the patient for the PPH (80). It has also been demonstrated that in elderly individuals, the intensity of postprandial hypotension and orthostatic hypotension are additive; however, their magnitude is not synergistic (80). While it was originally believed that postprandial hypotension was due to increased blood flow to the gut it now seems more likely to be due to the release of calcitonin gene related peptide (CGRP) which causes peripheral vasodilation (64).

Nonpharmacological treatment of PPH could be initiated by drinking warm water prior to having a meal. It has been shown that drinking $480 \mathrm{~mL}$ of water (at room temperature) could prevent the drop in blood pressure as much as $20 \mathrm{mmHg}$ in patients with autonomic dysfunction (81). Some of the commonly used medications for treatment of PPH are listed in Table $2(77,78,82)$ :

\section{The Role of Cardiac Autonomic Neuropathy in Syncope}

Autonomic neuropathy from a variety of causes is a major reason for arrythmias and sudden cardiac death (83). With aging autonomic neuropathy can occur at a level significant to cause arrythmias (84). This is especially true in persons with diabetes mellitus $(85,86)$. There is also a high rate of autonomic neuropathy in persons with dementia (87). Twentyfour hour measurement of heart rate variability would appear to be the best method to determine if a patient has cardiac autonomic neuropathy $(88,89)$. Insertion of a loop recorder should be considered in all patients with cardiovascular autonomic neuropathy (90). In patients with cardiac syncope due to bradycardia or asystole, a dual chamber pacemaker can significantly reduce the recurrence of episodes (90).

\section{Figure 3}

Pathophysiology of Postprandial Hypotension

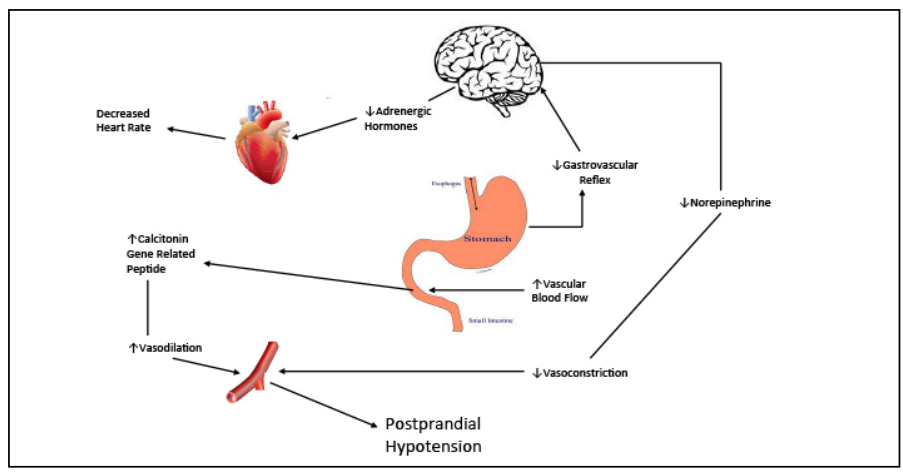

The most important step in evaluating a patient for neurally mediated syncope (also known as vasovagal syncope) is to exclude other diseases with similar presentations such as vertigo, seizures, pseudoseizures, cataplexy, hypoglycemia, fall secondary to gait abnormalities, leukoaraiosis, or polypharmacy $(39,91,92)$. The etiology of syncope related to autonomic neuropathy can be due to bradyarrythmias or arrythmmias and/ or hypotension.

Table 2

Medications used for the treatment of postprandial hypotension

\begin{tabular}{lll}
\hline Medication & Mechanism of Action & Dosage Form \\
\hline Liraglutide & Glucagon-like peptide-1 (GLP-1) slows gastric emptying & Subcutaneously \\
Acarbose/ & & \\
miglitol & $\alpha$-1-Glucosidase inhibitor - slows gastric emptying & Tablet \\
Guar gum & Slows gastric emptying & Powder \\
Octreotide & Increase splanchnic vascular resistance & Subcutaneously \\
\hline
\end{tabular}




\section{THE JOURNAL OF NUTRITION, HEALTH \& AGINGC}

The most common events which proceed to a syncopal episodes are stressful events, micturition, defecation, exercise, or pain (91). The typical prodromal symptoms are diaphoresis, nausea, and tunnel vision (93). The etiology of syncope could be divided in three categories: 1- autonomic dysfunction 2cardiac induced syncope 3-vascular occlusion or stenosis (93). All three mechanisms have a common end result which is decrease blood perfusion to the brain and result in transient loss of consciousness.

Head-up tilt test is the widely used test to evaluate a patient for vasovagal syncope (94). According to the American College of Cardiology/American Heart Association guidelines published on 2017 for treatment of vasovagal syncope in patients with prolonged prodromal period, patient's education to practice physical counter-maneuvers such as limb and/or abdominal contraction, squatting, or leg crossing could be significantly effective (95). Midodrine has been suggested for medical treatment of patients with recurrent episodes of vasovagal syncope (96). Other medications such as Fludrocortisone, Betablockers (in patients 42 year $<$ ), or selective serotonin reuptake inhibitor could also be beneficial (95). In treatment of patients with cardiac syncope secondary to symptomatic bradycardia or asystole, a dual chamber pacemaker would significantly reduce the recurrence of episodes (97).

Carotid sinus syndrome is seen in a patient with an extreme response to baroreceptor-mediated reflex stimulation which result in symptomatic bradycardia and possibly hypotension (8). Carotid sinus syndrome occurs after a carotid sinus massage which results an asystole for longer than 3 seconds (37).

\section{Conclusion}

Autonomic neuropathy is common in older persons particularly if they have diabetes mellitus - It is commonly a cause of syncope. Clinicians caring for older persons should always consider cardiovascular disease due to autonomic neuropathy in older persons with syncope.

\section{References}

1. Ropper, A. H. Adams and Victors principles of neurology. New York: McGraw-Hill Education Medical, 2014

2. Cardinali, D. P. Autonomic Nervous System: Basic and Clinical Aspects. Cham: Springer International Publishing, 2018.

3. Daroff, R. B. Bradley's neurology in clinical practice. London: Elsevier, 2016.

4. Hotta, H., \& Uchida, S. Aging of the autonomic nervous system and possible improvements in autonomic activity using somatic afferent stimulation. Geriatrics \& Gerontology International, 2010;10. doi:10.1111/j.1447-0594.2010.00592.x

5. Ko, D., Preis, S. R., Lubitz, S. A., Mcmanus, D. D., Vasan, R. S., Hamburg, N. M. Mitchell, G. F. Relation of Orthostatic Hypotension With New-Onse Atrial Fibrillation (From the Framingham Heart Study). The American Journal of Cardiology, 2018;121(5), 596-601. doi:10.1016/j.amjcard.2017.11.036

6. Benarroch, E. E. The clinical approach to autonomic failure in neurological disorders. Nature Reviews Neurology, 2014;10(7), 396-407. doi:10.1038/nrneurol.2014.88

7. Freeman, R. Neurogenic Orthostatic Hypotension. New England Journal of Medicine, 2008;358(6), 615-624. doi:10.1056/nejmcp074189

8. Halter JB, Ouslander JG, Studenski S, High KP, Asthana S, Supiano MA, Ritchie C eds. Hazzard's Geriatric Medicine and Gerontology, 7e New York, NY: McGraw-Hill

9. Juraschek, S. P., Daya, N., Rawlings, A. M., Appel, L. J., Miller, E. R., Windham, B. G., Selvin, E. Association of History of Dizziness and Long-term Adverse Outcomes With Early vs Later Orthostatic Hypotension Assessment Times in
Middle-aged Adults. JAMA Internal Medicine, 2017;177(9), 1316. doi:10.1001/ jamainternmed.2017.2937

10. Kasper, D. L., Fauci, A. S., Hauser, S. L., Longo, D. L., Jameson, J. L. \& Loscalzo, J. Harrisons principles of internal medicine. New York: McGraw Hill Education, 2015.

11. Freeman, R., Wieling, W., Axelrod, F. B., Benditt, D. G., Benarroch, E., Biaggioni, I., Dijk, J. G. Consensus statement on the definition of orthostatic hypotension, neurally mediated syncope and the postural tachycardia syndrome. Clinical Autonomic Research, 2011;21(2), 69-72. doi:10.1007/s10286-011-0119-5

12. Foster-Dingley, J. C., Moonen, J. E., Ruijter, W. D., Mast, R. C., \& Grond, J. V. Orthostatic hypotension in older persons is not associated with cognitive functioning, features of cerebral damage or cerebral blood flow. Journal of Hypertension, 2018;36(5), 1201-1206. doi:10.1097/hjh.0000000000001681

13. Luukinen, H., Koski, K., Laippala, P., \& Kivelä, S. Prognosis of Diastolic and Systolic Orthostatic Hypotension in Older Persons. Archives of Internal Medicine, 1999;159(3), 273. doi:10.1001/archinte.159.3.273

14. Mader, S. L. Low Prevalence of Postural Hypotension Among Community-Dwelling Elderly. JAMA: The Journal of the American Medical Association, 1987;258(11), 1511. doi:10.1001/jama.1987.03400110093033

15. Catz, A., Mendelson, L., \& Solzi, P. Symptomatic postprandial hypotension in high paraplegia. Case report. Spinal Cord, 1992;30(8), 582-586. doi:10.1038/sc.1992.118

16. Strogatz, D. S., Keenan, N. L., Barnett, E. M., \& Wagner, E. H. Correlates of Postural Hypotension in a Community Sample of Elderly Blacks and Whites. Journal of the American Geriatrics Society, 1991;39(6), 562-566. doi:10.1111/j.1532-5415.1991. tb03593.x

17. Kaufmann, H., Freeman, R., Biaggioni, I., Low, P., Pedder, S., Hewitt, L. A. Mathias, C. J. Droxidopa for neurogenic orthostatic hypotension: A randomized, placebo-controlled, phase 3 trial. Neurology, 2014;83(4), 328-335. doi:10.1212/ wnl.0000000000000615

18. Ricci F, Fedorowski A, Radio F, et al. Cardiovascular morbidity and mortality related to orthostatic hypotension: A meta-analysis of prospective observational studies. Eur Heart J 2015;36:1609-1617.

19. Fedorowski, A., Engström, G., Hedblad, B., \& Melander, O. (2010). Orthostatic Hypotension Predicts Incidence of Heart Failure: The Malmö Preventive Project. American Journal of Hypertension, 2010;23(11), 1209-1215. doi:10.1038/ ajh.2010.150

20. Goldstein, D. S. Dysautonomias: Clinical Disorders of the Autonomic Nervous System. Annals of Internal Medicine, 2002;137(9), 753. doi:10.7326/0003-4819-1379-200211050-00011

21. Ramirez, C. E., Okamoto, L. E., Arnold, A. C., Gamboa, A., Diedrich, A., Choi, L. Shibao, C. A. Efficacy of Atomoxetine Versus Midodrine for the Treatment of Orthostatic Hypotension in Autonomic Failure Novelty and Significance. Hypertension, 2014;64(6), 1235-1240. doi:10.1161/hypertensionaha.114.04225

22. Krolewski, A. S., Warram, J. H., Cupples, A., Gorman, C., Szabo, A., \& Christlieb, A. Hypertension, orthostatic hypotension and the microvascular complications of diabetes. Journal of Chronic Diseases, 1985;38(4), 319-326. doi:10.1016/00219681(85)90078-5

23. Shibao, C., Lipsitz, L. A., \& Biaggioni, I. Evaluation and treatment of orthostatic hypotension. Journal of the American Society of Hypertension, 2013;7(4), 317-324. doi:10.1016/j.jash.2013.04.006

24. Mancia, G., \& Grassi, G. Orthostatic hypotension and cardiovascular risk: Defining the epidemiological and prognostic relevance. European Heart Journal, 2009;31(1), 12-14. doi:10.1093/eurheartj/ehp389

25. Rutan, G. H., Hermanson, B., Bild, D. E., Kittner, S. J., Labaw, F., \& Tell, G. S Orthostatic hypotension in older adults. The Cardiovascular Health Study. CHS Collaborative Research Group. Hypertension, 1992;19(6_Pt_1), 508-519.

26. Phipps, M. S., Schmid, A. A., Kapoor, J. R., Peixoto, A. J., Williams, L. S., \& Bravata, D. M. Orthostatic hypotension among outpatients with ischemic stroke. Journal of the Neurological Sciences, 2012;314(1-2), 62-65. doi:10.1016/j. jns.2011.10.031

27. Frith, J., Ng, W., Day, C. P., Payne, B., Sheerin, N., Gorman, G. Newton, J. L. (2014). Orthostatic intolerance is common in chronic disease - A clinical cohort study. International Journal of Cardiology, 2014;174(3), 861-863. doi:10.1016/j. ijcard.2014.04.175

28. Gupta, V., \& Lipsitz, L. A. Orthostatic Hypotension in the Elderly: Diagnosis and Treatment. The American Journal of Medicine, 2007;120(10), 841-847. doi:10.1016/j.amjmed.2007.02.023

29. Morley, J. E. Frailty, Falls, and Fractures. Journal of the American Medical Directors Association, 2013;14(3), 149-151. doi:10.1016/j.jamda.2012.12.009

30. Ricci, F., Caterina, R. D., \& Fedorowski, A. Orthostatic Hypotension. Journal of the American College of Cardiology, 2015;66(7), 848-860. doi:10.1016/j. jacc.2015.06.1084

31. Boron, W. F., \& Boulpaep, E. L. Medical physiology. Chapter 2017;20, 461-482.e2 Philadelphia: Elsevier, 2017.

32. Dineen, J., \& Freeman, R. Autonomic Neuropathy. Seminars in Neurology, 2015;35(04), 458-468. doi:10.1055/s-0035-1558983

33. Kanjwal, K., George, A., Figueredo, V. M., \& Grubb, B. P. Orthostatic hypotension. Journal of Cardiovascular Medicine, 2015;16(2), 75-81, doi:10.2459/01. 


\section{AUTONOMIC NEUROPATHY AND CARDIOVASCULAR DISEASE IN AGING}

jcm.0000446386.01100.35

34. Low, P. A. Prevalence of orthostatic hypotension. Clinical Autonomic Research, 2008;18(S1), 8-13. doi:10.1007/s10286-007-1001-3

35. Goldstein, D. S., \& Cheshire, W. P. (2017). Beat-to-beat blood pressure and heart rate responses to the Valsalva maneuver. Clinical Autonomic Research, 2017;27(6), 361367. doi:10.1007/s10286-017-0474-y

36. Goldstein, D. S., \& Sharabi, Y. Neurogenic Orthostatic Hypotension: A Pathophysiological Approach. Circulation, 2009;119(1), 139-146. doi:10.1161/ circulationaha.108.805887

37. Sánchez-Ferro, Á, Benito-León, J., \& Gómez-Esteban, J. C. The Management of Orthostatic Hypotension in Parkinson's Disease. Frontiers in Neurology, 2013;4. doi:10.3389/fneur.2013.00064

38. Jones, P. K., Shaw, B. H., \& Raj, S. R. Orthostatic hypotension: Managing a difficult problem. Expert Review of Cardiovascular Therapy, 2015;13(11), 1263-1276. doi:10. 1586/14779072.2015.1095090

39. Morley, J. E., Rolland, Y., Tolson, D., \& Vellas, B. Increasing Awareness of the Factors Producing Falls: The Mini Falls Assessment. Journal of the American Medical Directors Association, 2012;13(2), 87-90. doi:10.1016/j.jamda.2011.11.002

40. Ci, W., \& E, T. Syncope: Dietary advice to help manage the symptoms of syncope. Integrative Food, Nutrition and Metabolism, 2016;3(5). doi:10.15761/ifnm.1000165

41. Gillis, D. J., Wouda, M., \& Hjeltnes, N. Non-pharmacological management of orthostatic hypotension after spinal cord injury: A critical review of the literature. Spinal Cord, 2008;46(10), 652-659. doi:10.1038/sc.2008.48

42. Arnold, A. C., \& Shibao, C. Current Concepts in Orthostatic Hypotension Management. Current Hypertension Reports, 2013;15(4), 304-312. doi:10.1007/ s11906-013-0362-3

43. Figueroa, J. J., Basford, J. R., \& Low, P. A. Preventing and treating orthostatic hypotension: As easy as A, B, C. Cleveland Clinic Journal of Medicine, 2010;77(5), 298-306. doi: 10.3949/ccjm.77a.09118

44. Fouad-Tarazi, F. M., Okabe, M., \& Goren, H. Alpha sympathomimetic treatment of autonomic insufficiency with orthostatic hypotension. The American Journal of Medicine 1995;99(6), 604-610. doi:10.1016/S0002-9343(99)80246-0

45. Hoeldtke, R. D., Davis, K. M., Joseph, J., Gonzales, R., Panidis, I. P., \& Friedman, A. C. Hemodynamic effects of octreotide in patients with autonomic neuropathy. Circulation, 1991;84(1), 168-176. doi:10.1161/01.cir.84.1.168

46. Hoeldtke, R. D., Horvath, G. G., Bryner, K. D., \& Hobbs, G. R. Treatment of Orthostatic Hypotension with Midodrine and Octreotide. The Journal of Clinical Endocrinology, \& Metabolism, 1998;83(2), 339-343. doi:10.1210/jcem.83.2.4534

47. Hoeldtke, R. D., \& Streeten, D. Treatment of Orthostatic Hypotension with Erythropoietin. New England Journal of Medicine, 1993;329(9), 611-615. doi:10.1056/nejm199308263290904

48. Kaufmann, H., Norcliffe-Kaufmann, L., \& Palma, J. Droxidopa in neurogenic orthostatic hypotension. Expert Review of Cardiovascular Therapy, 2015;13(8), 875891. doi:10.1586/14779072.2015.1057504

49. Mathias, C. J., Fosbraey, P., Costa, D. F., Thornley, A., \& Bannister, R. The effect of desmopressin on nocturnal polyuria, overnight weight loss, and morning postural hypotension in patients with autonomic failure. Bmj, 1986;293(6543), 353-354 doi: $10.1136 / \mathrm{bmj} .293 .6543 .353$

50. Maule, S., Papotti, G., Naso, D., Magnino, C., Testa, E., \& Veglio, F. Orthostatic Hypotension: Evaluation and Treatment. Cardiovascular \& Hematological DisordersDrug Targets, 2007;7(1), 63-70. doi:10.2174/187152907780059029

51. Mcdonald, C., Newton, J. L., \& Burn, D. J. Orthostatic hypotension and cognitive impairment in Parkinson's disease: Causation or association? Movement Disorders, 2016;31(7), 937-946. doi:10.1002/mds.26632

52. Metzler, M., Duerr, S., Granata, R., Krismer, F., Robertson, D., \& Wenning, G. K. Neurogenic orthostatic hypotension: Pathophysiology, evaluation, and management. Journal of Neurology, 2012;260(9), 2212-2219. doi:10.1007/s00415-012-6736-7

53. Omara, G., \& Lyons, D. Postprandial hypotension. Clinics in Geriatric Medicine, 2002;18(2), 307-321. doi:10.1016/s0749-0690(02)00012-5

54. Verwaerde, P., Tran, M., \& Montastruc, J. Effects of yohimbine, an $\alpha 2$-adrenoceptor antagonist, on experimental neurogenic orthostatic hypotension. Fundamental \& Clinical Pharmacology, 1997;11(6), 567-575. doi:10.1111/j.1472-8206.1997. tb00862.x

55. Lanier JB1, Mote MB, Clay EC. Evaluation and management of orthostatic hypotension. American Family Physician, 2011;84(5):527-536.

56. Wells R, Spurrier AJ, Linz D, et al. Postural tachycardia syndrome: Current perspectives. Vasc Health Risk Manag 2017;14:1-11.

57. Arnold AC, Ng J, Raj SR. Postural tachycardia syndrome - diagnosis, physiology, and prognosis. Auton Neurosci 2018;Feb 28. Doi: 10.1016/.autneu.2018.02.005 (Epub ahead of print).

58. Raj V, Opie M, arnold aC. Cognitive and psychological issues in postural tachycardia syndrome. Auton Neurosci 2018;Mar 27 doi: 10.1016/j.autneu.2018.03.004.

59. Garland EM, Celedonio JE, Raj SR. Postural tachycardia syndrome: Beyond orthostatic intolerance. Curr Neurol Neurosci Rep 2015;15:60. Doi: 10.1007/s11910015-0583-8.

60. Novak P. Orthostatic cerebral hypoperfusion syndrome. Front Aging Neurosci 2016;8:22. Doi: 10.3389/fnagi.2016.00022. eCollection.

61. Metwalley KA, Hamed SAA, Farghaly HS. Cardiac autonomic function in children with type 1 diabetes. Eur J Pediatr 2018;Mar 2. Doi: 10.1007/s00431-018-3122-1 [Epub ahead of print].

62. Kanjwal K, Karabin B, Kanjwal Y, Grubb BP. Autonomic dysfunction presenting as postural orthostatic tachycardia syndrome in patients with multiple sclerosis. Int J Med Sci 2010;7:62-67.

63. Ruzieh M, Grubb BP. Orthostatic intolerance and postural tachycardia syndrome: New insights into pathophysiology and treatment. Herzschrittmacherther Elektrophysiol 2018; Apr 25. Doi: 10.10007/s00399018-0563-1 [Epub ahead of print].

64. Edwards BJ, Perry HM 3rd, Kaiser FE, et al. Relationship of age and calcitonin generelated peptide to postprandial hypotension. Mech Ageing Dev 1996;87:61-73.

65. Seyer-Hansen K. Postprandial hypotension. Br Med J 1977;12:1262.

66. Trahair LG, Horowitz M, Jones KL. Postprandial hypotension: A systematic review. J A Med Dir Assoc 2014;15:394-409.

67. Jansen, R. W., \& Lipsitz, L. A. Postprandial Hypotension: Epidemiology, Pathophysiology, and Clinical Management. Annals of Internal Medicine, 1995;122(4), 286. doi:10.7326/0003-4819-122-4-199502150-00009

68. Zou, X., Cao, J., \& Li, J. Prevalence of and risk factors for postprandial hypotension in older Chinese men. Journal of Geriatric Cardiology, 2015;12(6), 600-604. doi:10.11909/j.issn.1671-5411.2015.06.003

69. Pavelić, A., Skorić, M. K., Crnošija, L., \& Habek, M. Postprandial hypotension in neurological disorders: Systematic review and meta-analysis. Clinical Autonomic Research, 2017;27(4), 263-271. doi:10.1007/s10286-017-0440-8

70. Teramoto, S., Akishita, M., Fukuchi, Y., Toba, K., \& Ouchi, Y. Assessment of Autonomic Nervous Function in Elderly Subjects with or without Postprandial Hypotension. Hypertension Research, 1997;20(4), 257-261. doi:10.1291/ hypres. 20.257

71. Aronow, W. S., \& Ahn, C. Association of Postprandial Hypotension with incidence of falls, syncope, coronary events, stroke, and total mortality at 29-month follow-up in 499 older nursing home residents. Journal of the American Geriatrics Society, 1997;45(9), 1051-1053. doi:10.1111/j.1532-5415.1997.tb05965.x

72. Barochiner J, Alfie J, Aparicio LS, et al. Postprandial hypotension detected through home blood pressure monitoring: A frequent phenomenon in elderly hypertensive patients. Hypertension Research, 2013;37(5), 438-443. doi:10.1038/hr.2013.144

73. Idiaquez, J., Rios, L., \& Sandoval, E. Postprandial hypotension in Alzheimers disease. Clinical Autonomic Research, 1997;7(3), 119-120. doi:10.1007/bf02308837

74. Tabara, Y., Okada, Y., Uetani, E., Nagai, T., Igase, M., Kido, T., Miki, T. Postprandial hypotension as a risk marker for asymptomatic lacunar infarction. Journal of Hypertension, 2014;32(5), 1084-1090. doi:10.1097/hjh.0000000000000150

75. Trahair, L. G., Horowitz, M., \& Jones, K. L. Postprandial Hypotension: A Systematic Review. Journal of the American Medical Directors Association, 2014;2014;15(6), 394-409. doi:10.1016/j.jamda.2014.01.011

76. Van Orshoven, N. P., Jansen, P. A., Oudejans, I., Schoon, Y., \& Oey, P. L. Postprandial Hypotension in Clinical Geriatric Patients and Healthy Elderly: Prevalence Related to Patient Selection and Diagnostic Criteria. Journal of Aging Research, 2010, 1-7. doi:10.4061/2010/243752

77. Luciano, G. L., Brennan, M. J., \& Rothberg, M. B. Postprandial Hypotension. The American Journal of Medicine, 2010;123(3). doi:10.1016/j.amjmed.2009.06.026

78. Morley, J. E. The Aging Gut: Physiology. Clinics in Geriatric Medicine, 2007;23(4), 757-767. doi:10.1016/j.cger.2007.06.002

79. Puisieux, F., Bulckaen, H., Fauchais, A. L., Drumez, S., Salomez-Granier, F., \& Dewailly, P. Ambulatory Blood Pressure Monitoring and Postprandial Hypotension in Elderly Persons With Falls or Syncopes. The Journals of Gerontology Series A Biological Sciences and Medical Sciences, 2000;55(9). doi:10.1093/gerona/55.9.m53

80. Maurer, M. S. Upright Posture and Postprandial Hypotension in Elderly Persons Annals of Internal Medicine, 2000;133(7), 533. doi:10.7326/0003-4819-133-7200010030-00012

81. Shannon, J. R., Diedrich, A., Biaggioni, I., Tank, J., Robertson, R. M., Robertson, D., \& Jordan, J. Water drinking as a treatment for orthostatic syndromes. The American Journal of Medicine, 2002;112(5), 355-360. doi:10.1016/s0002-9343(02)01025-2

82. Morley, J. E. Gait, Falls, and Dementia. Journal of the American Medical Directors Association, 2016;17(6), 467-470. doi:10.1016/j.jamda.2016.03.024

83. Lange-Maia BS, Newman AB, Jakicic JM, et al. Relationship between sensorimotor peripheral nerve function and indicators of cardiovascular autonomic function in older adults from the Health, Aging and Body Composition Study. Exp Gerontol 2017;96:38-45.

84. Agarwal G, Singh SK. Arrhythmias in Type 2 diabetes mellitus. Indian J Endocrinol Metab 2017;21:715-718.

85. Vinik AI, Erbas T Diabetic autonomic neuropathy. Handb Clin Neurol 2013;117:279294.

86. Morley JE, Asvat MS, Klein L, Lowenthal MN. Autonomic neuropathy in Black diabetic patients. S Am Med J 1977;52:115-116.

87. Allan LM, Ballard CG, Allen J, Murray A, Davidson AW, McKeith IG, Kenny RA. Autonomic dysfunction in dementia. J Neurol Neurosurg Psychiatry 2007;78:671677.

88. Taralov ZZ, Terziyski KV, Kostianev SS. Heart rate variability as a method for assessment of the autonomic nervous system and the adaptations to different physiological and pathological conditions. Folia Med (Plovdiv) 2015;57:173-180 


\section{THE JOURNAL OF NUTRITION, HEALTH \& AGINGC}

89. da Silva VP, Ramalho Oliveira BR, Tavares Mello RG, et al. Heart rate variability idexes in dementia: A systematic review with a quantitative analysis. Curr Alzheimer Res 2018;15:80-88.

90. Sciaraffia E, Chen J, Hocini M, et al. Use of event recorders and loop recorders in clinical practice: Results of the European Heart Rhythm Association survey. Europace 2014;16:1384-1386.

91. Kapoor, W. N. Syncope. New England Journal of Medicine, 2000;343(25), 18561862. doi: $10.1056 /$ nejm200012213432507

92. Morley, J. E. White Matter Lesions (Leukoaraiosis): A Major Cause of Falls. Journal of the American Medical Directors Association, 2015;16(6), 441-443. doi:10.1016/j. jamda.2015.03.023

93. Fox, M. C., Lakdawala, N., Miller, A. L., \& Loscalzo, J. A Patient with Syncope. New England Journal of Medicine, 2013;369(10), 966-972. doi:10.1056/ nejmcps 1300093

94. Makowiec, D., Graff, B., \& Struzik, Z. R. Multistructure index characterization of heart rate and systolic blood pressure reveals precursory signs of syncope. Scientific Reports, 2017;7(1). doi:10.1038/s41598-017-00354-x

95. Shen, W., \& Sheldon, R. S. Assessment and Treatment of Syncope. JAMA Cardiology, 2017;2(8), 920. doi:10.1001/jamacardio.2017.1784

96. Shen, W., Sheldon, R. S., Benditt, D. G., Cohen, M. I., Forman, D. E., Goldberger, Z. D,Yancy, C. W. 2017 ACC/AHA/HRS Guideline for the Evaluation and Management of Patients with Syncope: A Report of the American College of Cardiology/American Heart Association Task Force on Clinical Practice Guidelines and the Heart Rhythm Society. Circulation, 2017;136(5). doi:10.1161/cir.0000000000000499

97. Palmisano, P., Accogli, M., Zaccaria, M., Luzzi, G., Nacci, F., Anaclerio, M., \& Favale, S. Predictive factors for pacemaker implantation in patients receiving an implantable loop recorder for syncope remained unexplained after an extensive cardiac and neurological workup. International Journal of Cardiology, 2013;168(4), 3450-3457. doi:10.1016/j.ijcard.2013.04.179 